\title{
ON DIGITAL READING
}

This paper examines possible relations between traditional reading and digital reading. A hypothesis that "digital reading" is more of a metaphor than reading in the traditional sense is advocated through pointing out the differences in organization of information space, linear/nonlinear text structure and required literacy. Also, new readability formula is proposed.

Key words: "reading", etymology, Guttenberg area, digital reading, digital readability.

\section{Introduction}

"Reading" is the subject of research in many areas nowadays, most notably in information science, psychology and sociology. While information science approaches reading from the point of view of communicating information, psychology examines reading as "a complex, multi-component and multi-level dynamic psychological process"1), and sociology sees reading as "a non-individual cognitive activity but a productive collective activity"2). Moreover, a new category of reading - digital reading - emerged due to advances in ICT. Digital reading seen through the optics of information science is a completely new phenomenon ${ }^{3)}$. It adds new dimensions to the concept of reading. These new dimensions lead to the hypothesis that "digital reading" is more of a metaphor than reading in its traditional sense. In this article we look for evidence of such view. The article is organized as follows: in the first chapter, etymology of the word "reading" is discussed; the second chapter briefly discusses the concept of reading since Guttenberg's invention of the printing press. The specifics of digital reading are pointed out in the third chapter; a new readability formula is proposed in the fourth chapter and, finally, conclusions are formulated.

\section{The etymology of the word "reading"}

To our knowledge, the etymology of the word "reading" in Slovak language has not been published yet. It seems that, similarly to other Slavic languages, the verb "citat" refers to "counting something”. As for non-Slavic languages, elsewhere in literature we can learn that "reading" has its origin in ancient Greek word "legein", which means "to say" or "to declare"; in Old Latin the equivalent of "reading" is "lignum" meaning "that which is gathered" etymology of the word "reading" in most Roman languages also goes back to Latin - "leggere" in Italian, "lire" in French or "leer" in Spanish. It can be observed that while the Greek word "legein" points out to an act of speech, or in other words, that reading is another way of processing speech, a significant shift in the meaning can be found in Latin - "to gather" is close to Slovak notion of "counting something". The etymology of "reading" is also briefly discussed by Senn ${ }^{5)}$. He concludes that "In English the verb is related to acts of guessing, advising or riddles; Latin and German take their metaphor from collecting ("legere", "lesen"). The Greek word anagignoskein (related to "know") takes it originally as a process of recognition, an ongoing one as its ending in -skein informs us ... we put items together, we guess, and we may chancily recognize something we already know".

\section{The concept of reading in Guttenberg era}

Gutenberg's invention of printing press gave birth not only to books but also to a new type of literacy where the ability to read plays a key role. Since then the process of reading has been analysed numerous times. Theories on reading can by classified into three categories $^{6}$ :

- The traditional view: Readers passively receive information from the text through decoding printed symbols into their aural equivalents and consequent allocation of meaning.

\footnotetext{
* Milan Martin Konvit

Faculty of Humanities, University of Zilina, Slovakia, E-mail: milan.konvit@fpv.uniza.sk

${ }^{1)}$ ZAPOTOCNA, O., GAVORA, P. (Eds.): The Central European Conference on Reading. Abstract of Papers. 2000. SRA-SLJS, ISBN: 80-968403-04, p. 82

2) HRUBY, G. G.: Sociological, postmodern, and new realism perspectives in social constructionism: Implications for literacy research. 2001.

3) Digital reading is also subject of research in pedagogy. We will not deal with its result in this paper.

4) Online Etymology Dictionary. 〈http://www.etymonline.com/index.php?term=lecture>.

${ }^{5)}$ SENN, F. Joycean Murmoirs: Fritz Senn on James Joyce. 2007, ISBN-13: 978-1843511250

${ }^{6)}$ VAEZI, S. Theories of fading.
} 
- The cognitive view: Active readers sample the text and in an iterative manner make hypotheses on meaning that they later confirm or reject.

- Metacognitive view: According to Klein et al. (1991) ${ }^{7}$, active readers sequentially pass through several stages: identification of a need to read, identification of a form/type of the text to be read, identification of general text feature, guessing the author's message hidden in the text, predicting what will come next. The reading process can be thus described by the following equation:

understanding $=$ prior knowledge + forecast of meaning

The objective of reading is not an act of reading itself but an act of understanding and subsequent exploitation of information received either on practical or aesthetical levels. However, from the point of view of understanding, reading is a hierarchical process with four stages of reading:

1. Elementary reading,

2. Explorative reading,

3. Analytical reading,

4. Synoptic reading.

\section{Specifics of digital text}

Let us now take a look at the specifics of digital texts:

- space limitation (while a book is always limited to a finite number of pages, digital text is theoretically unlimited)

- different type of physical carrier (paper versus electronic signal),

- wider scale of modes of information (alphanumerical text, audio, picture, video, multimedia),

- text computability (ability to process the text by computer),

- shape of information spaces and possibility of transfers among them.

\section{Specifics of reading of digital text}

Process of reading of digital text is influenced by hypertextual character of digital texts, cultural context (from local to global) and feature of interactivity. Among the above mentioned differences, the following three are considered key differences:

1. nonlinear structure of digital text,

2. size of accessible texts,

3. possibility to change not only the form of the text but also the text itself (i.e. computability of text.

All these three differences result in completely different nature of digital reading. Digital reading has not such depth as traditional one. The term "surfing" is good approximation of the digital reading process.

\section{New readability formula}

The term "readability" is used in connection with texts printed on paper; it denotes the ease with which a text can be read and, most importantly, understood. On the other hand, "readability" used in connection with displaying text on a screen is aimed at improving the screen design by choosing proper fonts, font sizes, colours, arrangement of texts and pictures or various technological effects. In other words, "readability" objectives target the most basic level of reading process, namely the improvement of sensation of isolated text symbols. We will extend the meaning of "readability" further into the area of comprehension of digital information spaces, and, therefore, denote this kind of extended readability as "digital readability".

\subsection{Readability of printed text}

Numerous readability tests can be found in literature. In English speaking countries three following methods are especially popular: - Readability Formula designed by E. Fry ${ }^{8)}$

- Grade Level Readability Formula by R. Flesch" ${ }^{9}$,

- Fog Index constructed by R. Gunning ${ }^{10)}$.

Sentence length and word length are key indicators of text complexity. However, not all long words are equally difficult to read. Hence, familiarity with words and vocabulary richness are used as supporting readability indicators. Too many unfamiliar words can block the cognitive process. This is the reason why some formulas, e.g. Dale - Chail formula ${ }^{11}$, use different lists of "hard" words. Similarly, vocabulary too rich (i.e. too many different terms in a text) make understanding the text read difficult.

Fry's algorithm for design of readability diagram consists of the following steps:

1. Random selection of three unrelated 100 -word texts.

2. Counting the number of sentences in each text.

3. Counting the number of syllables in each text.

4. Plotting the average sentence length and the average number of syllables

( $\mathrm{y}$ - average number of sentences, $\mathrm{x}$ - average number of syllabus per 100 words).

The area covered by the graph designates "complexity" of a given text.

\footnotetext{
7) KLEIN, M. L., PETERSON, S., SIMINGTON, L. Teaching Reading in the Elementary Grades, Allyn \& Bacon. ISBN-13: 978-0205128464, 1991.

8) FRY, E. A Readability Formula that Saves Time. 1968.

9) FLESCH, R. A new readability yardstick.1948.

10) GUNNING, R. The Technique of Clear Writing. 1971.

${ }^{11)}$ DALE, E., CHALL, J.S. Readability revisited: The New Dale-Chall Readability Formula. 1995.
} 
The Flesch Grade Level Readability algorithm is described by the following formula:

$F G L$ index $=206.835-(1.015 *$ average number of words used per sentence $)-(84.6$ * average number of syllables per word $)$

FGL index spans from 0 to 100 . The higher the index, the better the readability of the text. FGL index between 60 and 70 indicates readable and, at the same time, not too trivial texts.

The Gunning Fog Index is calculated using the following formula:

$$
G F I=0.4(A N W+P L W)
$$

Where $A N W$ is the average number of words per sentence, $P L W$ is the percentage of long words out of the total number of words in the text. The higher the GFI, the less readable the text. GFI above 20 is typical for scientific texts, law or government documents. In general, GFI is a good indicator of a text that is difficult to read.

The Dale-Chall Readability Index is defined by the following formula:

$$
D C \text { index }=0.1579 D W+0.0496 S L=3.6365
$$

Where $D W$ denotes the percentage of so-called difficult words (special list of words), $S L$ denotes the Average Sentence Length (expressed by the number of words).

$D C$ index on scale from 0 to 9 represents texts easily comprehensible even to people with only primary education. Index higher than 10 indicates that a college degree is required in order to fully understand the text.

\subsection{Digital readability}

The term "digital readability" will be used in order to stress the fact that we live in a digital environment. Digital readability consists of two parts:
- Traditional readability determined by identical parameters as readability of text printed on paper.

- Readability of digital information space that results in additional difficulties in text comprehension due to nonlinearity of digital information spaces. In order to overcome this obstacle, a new kind of literacy is necessary.

Among the formulas of text readability described above, The Gunning Fog Index seems to be the most suitable basis of digital readability standard design. We propose the following modification to Gunning formula:

$$
D G F I=q_{D L} \cdot q_{D R}\{0,4(A N W+P L W)\}
$$

Where DGFI is digital Gunning Fog Index, $q_{D L}$ is the digital literacy quotient* $<1, q_{D R}$ id digital readability index $<1, A N W$ is average number of words per sentence and $P L W$ is the percentage of long words out of the total number of words in the digital text.

\section{Conclusions}

According to available predictions of future developments, digital publications will exceed those in print in year 20xx, where years xx vary in literature between 2015 to 2030 . Another fact that has to be taken into account is the growing number of hours people spend in front of their computer screens. These two facts accelerate the urgency of research on digital reading. Results of such research should tell us how to write digital texts in order to make them more readable. Some preliminary results obtained from research carried out in a frame of KEGA project No. 3/7177/09 indicate that more attention should be paid to creation of hypertext information spaces. Heterogeneity of styles of different parts of such space, differences in vocabulary, different approaches to subject matter make such digital text less readable that traditional linear text. On the other hand, hypertext structure opens the door for presentation of different views and hierarchical organization of text. Our position is that digital reading should be subject of teaching in the same way as it is in case of traditional reading.

\section{References}

[1] ZAPOTOCNA, O., GAVORA, P. (Eds.): The Central European Conference on Reading. Abstract of Papers. Bratislava : SRA-SLJS, 2000. ISBN: 80-968403-0-4, p. 82.

[2] HRUBY, G. G.: Sociological, Postmodern, and New Realism Perspectives in Social, Constructionism: Implications for Literacy Research, 2001.

[3] Constructionism: Implications for Literacy Research. Reading Research Quarterly, 36, [online]. 2001[cit. 2001-06-20]. Available online: 〈www.catchword.com/ira/00340553/v36n1/contp11.htm>.

[4] Online Etymology Dictionary [online]. [cit. 2001-06-20]. Available online: 〈http://www.etymonline.com/index.php?term=lecture>.

\footnotetext{
* Magnitude of quotients $q_{D L}, q_{D R}$, is subject of research supported by KEGA project No. 3/7177/09
} 
[5] SENN, F.: Joycean Murmoirs: Fritz Senn on James Joyce. Edited by C. O’Neill. Dublin : The Lilliput Press, 2007, ISBN-13: 9781843511250.

[6] VAEYI, S: Theories of fading [online]. [cit. 2001-06-20]. Available online: <http://www.teachingenglish.org.uk/think/articles/theories-reading>.

[7] KLEIN, M. L., PETERSON, S., SIMINGTON, L.: Teaching Reading in the Elementary Grades, Allyn \& Bacon. ISBN-13: 9780205128464, 1991

[8] FRY, E. A: Readability Formula that Saves Time. In: J. of Reading, vol. 11, no. 7, 1968, pp. 513-16, 575-78.

[9] FLESCH, R.: A new Readability Yardstick. In: J. of Applied Psychology, 32, pp. 221-233, 1948.

[10] GUNNING, R.: The Technique of Clear Writing. New York: McGraw Hill, 1971.

[11] DALE, E., CHALL, J. S.: Readability revisited: The New Dale-Chall Readability Formula. Cambridge, Mass : Brookline Books, 1995, 149 p, ISBN 1571290087. 